ECONOMÍA: Teoría y Práctica • Nueva Época, número 45, julio-diciembre 2016, pp. 39-66, http://www.izt.uam.mx/economiatyp/ojs

\title{
La manufactura y la industria automotriz en cuatro regiones de México. Un análisis de su dinámica de crecimiento, 1980-2014*
}

\section{Manufacturing Production and the Automotive Industry in Four Regions of Mexico. An Analysis of Their Growth Dynamics, 1980-2014}

\author{
Yolanda Carbajal Suárez,** Leobardo de Jesús Almonte *** \\ y Pablo Mejía Reyes****
}

\begin{abstract}
RESUMEN
Se analiza la gradual concentración de la industria automotriz en cuatro regiones específicas de México y se plantea la hipótesis de que ha desempeñado un papel importante en el impulso de la manufactura en los estados donde se ha consolidado como una de las actividades más importantes, por su aportación al PIB estatal, al producto manufacturero nacional y a la generación de empleos. Para evaluarla, se estima un modelo econométrico con datos de panel cuyos resultados sugieren una importancia relativa del crecimiento de la industria automotriz en la explicación de la dinámica del producto manufacturero.
\end{abstract}

Palabras clave: industria automotriz, producto manufacturero, crecimiento económico, leyes de Kaldor, modelos de panel.

Clasificación JEL: O14, R11, R12.

\begin{abstract}
This paper analyzes the gradual concentration of the automotive industry in four specific regions of Mexico and argues that it has played a central role in the impulse of the manufacturing production in the states where this one has become one of the most important activities as measured by its contribution to the state GDP, the national manufacturing production and the generation of employment. To test this hypothesis, a panel data econometric model is estimated; the results suggest a relative importance of the growth of the automotive industry in explaining the dynamics of the manufacturing output.
\end{abstract}

Keywords: automotive industry, manufacturing production, economic growth, Kaldor's laws, Panel Data Models.

JEL classification: O14, R11, R12.

\footnotetext{
* Fecha de recepción: 01/09/2014. Fecha de aprobación: 19/02/2016.

** Universidad Autónoma del Estado de México. Correo electrónico: yolanda_carbajal@ hotmail.com.

*** Universidad Autónoma del Estado de México. Correo electrónico: 1dejesusa@uaemex.mx. **** Universidad Autónoma del Estado de México. Correo electrónico: pmejiare@uaemex.mx.
} 


\section{INTRODUCCIÓN}

La industria automotriz es considerada un sector estratégico para la actividad económica por el dinamismo que imprime tanto a la manufactura como a muchas otras actividades productivas de las zonas donde se ubica. Por ello, ha sido materia de análisis en un considerable número de trabajos tanto a nivel internacional como nacional.

Entre los resultados reportados en la literatura destaca que el surgimiento de sistemas regionales de producción ha propiciado la integración vertical de esta industria, con actividades tanto en países en desarrollo como desarrollados (Humphrey y Memedovic, 2003; Sturgeon et al., 2009). También se ha analizado el papel de los proveedores regionales (Sturgeon y Florida, 2000) y la forma en la que ha cambiado la geografía de la producción a partir de que esta industria se concentra en unas pocas grandes empresas (Sturgeon et al., 2009).

Por otro lado, se pueden mencionar los estudios de Dussel (2012), quien realiza un análisis comparativo de la cadena de autopartes en China y en México, destacando la transformación del primero en líder mundial, y Álvarez (2010), que enfatiza las estrategias instrumentadas por el gobierno de Brasil, las cuales han permitido el desarrollo de un importante número de productores locales de autobuses y chasís y la diversificación de las exportaciones. En el caso de México, por el contrario, Álvarez (2010) refiere que la crisis de 2008 generó una severa contracción en el sector como consecuencia del elevado nivel de importaciones de autopartes y componentes, de la escasa diversificación de sus exportaciones y de la ausencia de procesos de innovación tecnológica (véase, también, Godínez, 2007).

Finalmente, algunos autores han destacado la evolución de esta industria en México desde su inicios, con la instalación de las primeras armadoras, hasta su etapa exportadora en la fase de apertura económica (Camarena, 1981; Moreno-Brid, 1996; Vieyra, 1999; 2000; Vicencio, 2007); otros la han analizado desde una perspectiva regional o de conglomerado (Unger, 2004; Carbajal, 2012; 2013; 2015; Carbajal y De Jesús, 2013) o se han centrado en el estudio de la producción de autopartes (Juárez, 2005; Lara, Trujano y García, 2005; Álvarez y Cuadros, 2012) y algunos más la han abordado en el marco de periodos o hechos específicos que han marcado a este sector (Dombois, 1990; Carrillo y Ramírez, 1997).

Aun cuando en casi todos estos trabajos se hace referencia a la importancia de la industria automotriz como generadora de encadenamientos productivos 
con otras industrias, la evidencia específica existente de un fuerte vínculo con la manufactura es escasa. Destaca la investigación de Galicia-Bretón y SánchezJuárez (2011), quienes exponen las fallas de los organismos gubernamentales y privados para conformar una cadena productiva a partir de la instalación de la Ford Motors Company en Hermosillo, Sonora, dado que a partir de los años ochenta el enfoque de las políticas federales y estatales de fomento industrial se dirigió exclusivamente a apoyar a la gran industria trasnacional, dejando fuera a las empresas locales.

Se ha argumentado, además, que los encadenamientos del sector automotriz con otras industrias le permiten participar de forma directa e indirecta en gran cantidad de actividades económicas e influir sobre el resto de los sectores (Chamarro, 2013), dado que al mismo tiempo que genera empleos, transfiere tecnología y atrae inversiones. Más aún, por su naturaleza, puede revolucionar los procesos organizacionales y productivos para después difundirlos a las demás actividades económicas, como sugiere Maldonado (1995).

En México, esta industria ha desarrollado importantes encadenamientos productivos con las industrias del vidrio, el acero, el hierro, el hule, el plástico, el aluminio y la textil (Secretaría de Economía, 2012), con lo que ha llegado a convertirse en un importante dinamizador de la manufactura y de la actividad económica en los municipios y regiones donde se localiza.

Como se observa, la importancia del sector es evidente. En México, contribuye con $2.9 \%$ del producto interno bruto (PIB) total nacional y con $17.1 \%$ del manufacturero (INEGI, 2014a). Genera 3.3\% del empleo total nacional y $14.2 \%$ del manufacturero, concentra $17.5 \%$ del total de las remuneraciones monetarias (INEGI, 2014b) y, en 2013, las ventas automotrices al exterior representaron $25.2 \%$ del total de las exportaciones mexicanas, superando a las petroleras y a las de equipo y aparatos eléctricos y electrónicos (Asociación Mexicana de la Industria Automotriz, 2014). Este sector también es uno de los mayores receptores de inversión extranjera directa (IED): de 1999 al segundo trimestre de 2016 captó USD 45687.5 millones, lo que representa 10.2\% del total de la IED en México durante dicho periodo y $21 \%$ del total de la recibida por el sector manufacturero (Secretaría de Economía, 2016).

El planteamiento central de este artículo es que las entidades federativas de México y las regiones en las que se localiza la industria automotriz son también aquellas en las que la actividad económica muestra un mayor dinamismo y, particularmente, donde el sector manufacturero se ha consolidado como uno de los más importantes. Con este enfoque, el objetivo es identificar las regularida- 
des más significativas de la relación entre industria automotriz y manufactura. Se parte de evidenciar la concentración paulatina del sector en cuatro regiones específicas de México, para después analizar, a partir de una analogía de la primera ley de Kaldor, si la industria automotriz puede ser considerada como un motor de crecimiento manufacturero en las entidades federativas y, de forma agregada, en las regiones donde se ubica.

Se busca destacar la importancia de la relación industria automotriz-manufactura con el argumento de que no todos los sectores económicos tienen un mismo peso, sino que existen unos más importantes que otros y, en la práctica, el crecimiento agregado de una economía está relacionado con el sector cuya actividad presenta características más favorables (Thirlwall, 2003). El estudio se enfoca en el periodo 1980-2014 y en el análisis de las entidades federativas que integran las siguientes regiones: 1) Centro, integrada por la Ciudad de México, Estado de México, Puebla y Morelos. 2) Norte, formada por Chihuahua, Coahuila, Nuevo León, Sonora y Tamaulipas, 3) Centro-Norte, compuesta por San Luis Potosí, Querétaro y Guanajuato. 4) Occidente, que incluye Jalisco y Aguascalientes.

El trabajo se divide en cuatro apartados, además de la introducción y las conclusiones. En el primero se presentan algunas consideraciones teóricas relacionadas con la primera ley de Kaldor, que destaca la fuerte relación de causalidad entre el crecimiento del producto manufacturero y el del PIB. En el segundo, se analiza la concentración del sector automotriz en México y se identifican cuatro regiones en las que se concentra la mayoría de las plantas armadoras y las productoras de partes. En el tercero, se destaca la relación entre el sector automotriz y la expansión de la manufactura en las regiones identificadas y se argumenta que en las entidades federativas con mayor crecimiento automotriz también son en las que la manufactura ha presentado incrementos más importantes. Finalmente, se estima un modelo de panel para el crecimiento manufacturero: se hace una analogía con la primera ley de Kaldor y se extiende el análisis a otras variables explicativas de la expansión de la manufactura, sobre todo, el papel del avance automotriz como impulsor del sector manufacturero.

\section{CONSIDERACIONES TEÓRICAS}

El análisis del crecimiento económico generalmente se aborda a partir de modelos teóricos agregados y se asume que la economía es homogénea, tanto sectorial como regionalmente. Estos enfoques no consideran de forma explícita a un sector más importante que a otro (Thirlwall, 2003). Sin embargo, en la práctica, el 
crecimiento agregado puede estar condicionado por sectores específicos cuya actividad económica impulsa la expansión de los demás.

A decir de Thirlwall (2003), Nicholas Kaldor fue de los primeros que abordaron el tema del crecimiento a partir del comportamiento de los sectores, específicamente, la manufactura. Argumentaba que es imposible entender el proceso de crecimiento y desarrollo sin tener un enfoque sectorial que distinga entre actividades con rendimientos crecientes, por un lado (que se asocian con la industria), y actividades con rendimientos decrecientes (asociadas con actividades agrícolas y mineras).

Para Kaldor (1966; 1970), son esenciales las actividades en las que un país o una región se especializa, sobre todo, porque determinarán su nivel de desarrollo. En este sentido, considera a la manufactura como motor del crecimiento económico y sostiene que la especialización en la producción de bienes finales con alto contenido tecnológico permite desarrollar economías de escala relacionadas con el aprendizaje, lo que aumenta la productividad y, con ello, la producción.

Así, una región o país especializado en manufacturas tenderá a crecer y divergir respecto de los que se especializan en actividades agropecuarias y/o de servicios. Es decir, los países o regiones que posean una mayor demanda manufacturera, tendrán mayores posibilidades de incrementar su producción.

Estos argumentos se basan en tres regularidades empíricas (Kaldor, 1966; 1970) que dieron lugar a las tres leyes de Kaldor. ${ }^{1}$ En específico, la primera ley dicta que existe una fuerte relación de causalidad entre el crecimiento del producto manufacturero y el crecimiento del PIB (Kaldor, 1966). ${ }^{2}$ En esta relación, la existencia de rendimientos crecientes a escala, estáticos y dinámicos, en la industria manufacturera son esenciales porque su carácter macroeconómico convierte al sector industrial en motor del crecimiento (Moreno, 2008). ${ }^{3}$ De manera formal, la primera ley supone la siguiente relación:

$$
y_{t}=\alpha_{0}+\alpha_{1} y_{t}^{m}
$$

\footnotetext{
${ }^{1}$ Thirlwall (2003) explica las leyes de Kaldor de manera puntual y analítica.

${ }^{2}$ No es objetivo de este apartado hacer una revisión minuciosa y detallada de las leyes de Kaldor, sólo destacar el sentido analítico de la primera.

${ }^{3}$ Véase, también, Sánchez (2012), quien destaca las virtudes de la manufactura en el crecimiento económico; entre ellas, que es un sector de actividades con rendimientos crecientes, con una elasticidad ingreso de la demanda elevada, que son fuente importante de innovación y difusión tecnológica $\mathrm{y}$, sobre todo, sus encadenamientos productivos hacia adelante y hacia atrás con el resto de los sectores.
} 
donde $y_{t}$ es la tasa de crecimiento del PIB total y $y_{t}^{m}$ es la tasa de crecimiento de la producción manufacturera; $\alpha_{0}$ es el intercepto y $\alpha_{1}$ es el coeficiente que indica cuánto varía el producto total a medida que el producto manufacturero se incrementa en $1 \%$.

Aun cuando la literatura reciente da cuenta de aplicaciones de las leyes de Kaldor a la economía mexicana (Sánchez y Campos, 2010; Sánchez, 2012), Rendón-Rojas y Mejía (2015) han realizado una analogía de dichas leyes para explicar el crecimiento del sector manufacturero del Estado de México. La hipótesis que plantean es que los subsectores (de la Clasificación Mexicana de Actividades y Productos) 35 Sustancias químicas, productos derivados del petróleo y del carbón, hule y plásticos, y 38 Productos metálicos, maquinaria y equipo son fundamentales en la explicación del crecimiento manufacturero total, debido a que se caracterizan por ser modernos, dinámicos, con procesos tecnológicos avanzados e innovación constante.

Con esa lógica, dadas las características de la industria automotriz, en este artículo se busca determinar si la industria automotriz es un sector que dinamiza e impulsa la manufactura y, en consecuencia, el crecimiento de las regiones en las que se localiza. Más aún, se busca determinar si existe una relación de causalidad entre el incremento de la producción automotriz y el de la rama manufacturera.

Para tal efecto, se hace una analogía de la primera de ley de Kaldor, como en Rendón-Rojas y Mejía (2015), y se estima un modelo con datos de panel para explicar la importancia relativa de la producción automotriz en el crecimiento manufacturero de cuatro regiones de México. Los resultados se discuten con detalle en el apartado IV.

\section{LA CONCENTRACIÓN DEL SECTOR AUTOMOTRIZ EN CUATRO REGIONES DE MÉXICO}

Aun cuando la industria automotriz está presente en gran parte del territorio mexicano, es posible delimitar cuatro regiones predominantes donde actualmente se concentra la mayoría de las armadoras y las productoras de partes (mapa 1). El arribo y el posterior crecimiento de esta industria en las diferentes entidades federativas que integran estas regiones han respondido a lógicas diferentes; sin embargo, en todas y cada una de ellas ha llegado a convertirse en una de las actividades más dinámicas y representativas como resultado de su aportación al PIB total, pero sobre todo al manufacturero, así como por los empleos directos e indi- 
Mapa 1. México: concentración del sector automotriz por regiones

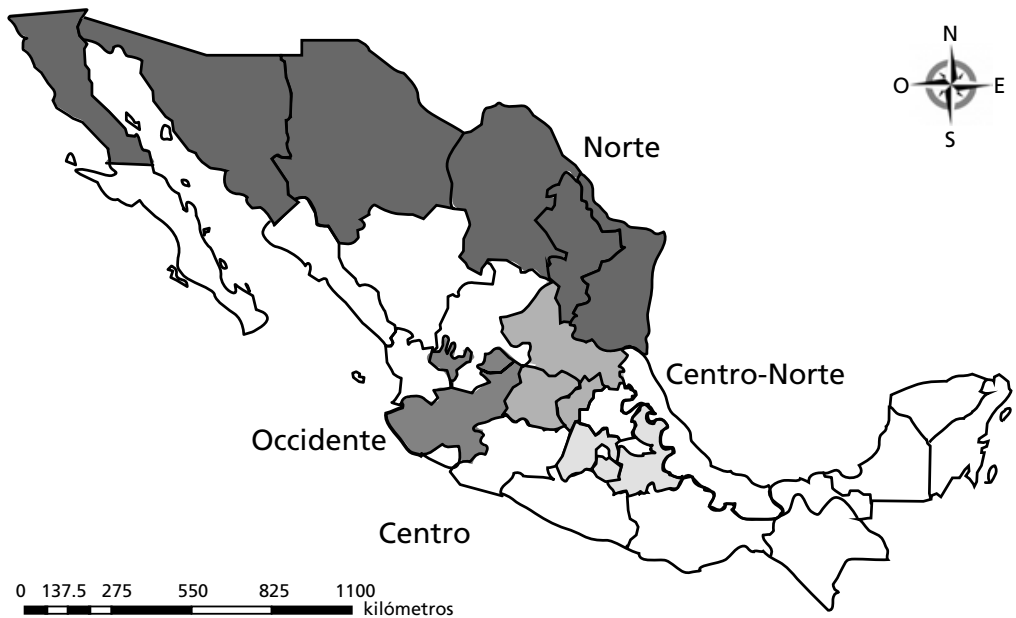

Fuente: Elaborado con ArcMap 10.1.

rectos que ha creado y, desde luego, por los encadenamientos productivos hacia atrás y hacia adelante que mantiene con otras actividades de la manufactura.

En principio, se encuentra la región Centro, donde se localiza la parte tradicional y más antigua del sector. Las entidades que la conforman son Puebla, Morelos, Estado de México y Ciudad de México. Estas dos últimas son representativas del inicio de la industrialización del país; en ellas se asentaron las primeras armadoras que se establecieron en México, con el propósito principal de abastecer el mercado interno en un periodo caracterizado por una economía cerrada y altamente protegida. Hasta antes de los ochenta representaba la región de mayor crecimiento para el sector, favorecida entonces por las medidas del gobierno federal para promover el desarrollo industrial (Villarreal y Villegas, 2005).

Sin embargo, la política de desconcentración ${ }^{4}$ que se dio a principios de los setenta y la competencia mundial con las armadoras japonesas obligaron a las empresas localizadas en México, básicamente las estadounidenses Chrysler, Ford y General Motors, a ubicarse en otras zonas y entidades. De esta forma,

\footnotetext{
${ }^{4}$ Política que se expresó en los decretos de Descentralización Industrial, de 1971-1972, así como en el primer Plan Nacional de Desarrollo Urbano, de 1978, que tenía como propósito principal la descentralización industrial de la Ciudad de México y el impulso al crecimiento de las ciudades intermedias. Para mayor detalle, véase Garza (1992).
} 
gran parte del impulso del sector se transfirió a otras regiones, de inicio a la Norte, en detrimento de la Centro. No obstante, el sector automotriz continúa siendo clave para la actividad económica de esta última.

Otro factor importante que contribuyó a la pérdida de dinamismo del sector automotriz en la región Centro fue la puesta en marcha del Tratado de Libre Comercio de América del Norte (TLCAN). Éste significó un nuevo orden económico y comercial a partir de que las grandes trasnacionales fijaron sus expectativas de crecimiento en los mercados externos, lo que convirtió en una ventaja la cercanía con los mercados estadounidense y canadiense; así, las entidades federativas de la franja fronteriza con Estados Unidos se convirtieron en receptores naturales de las nuevas inversiones automotrices.

En el cuadro 1 se hace evidente que la participación de la industria automotriz de la región Centro, con respecto a la nacional, ha disminuido considerablemente de 1980 a 2014. La proporción de unidades económicas pasó de 48.6\% a $26.6 \%$, aunque las caídas más dramáticas se han presentado en la generación del valor agregado censal bruto (VACB) y en la población ocupada (PO), pues estas variables redujeron su participación hasta en casi cincuenta puntos porcentuales en este periodo.

Por entidad federativa, las reducciones más importantes se han presentado en el Estado de México y la Ciudad de México (cuadro 1), entidades en las que en algún momento se concentró la mayor parte de la industria automotriz, pero que, como ya se mencionó, se vieron desplazadas como destinos de los flujos de inversión del sector ante las políticas de descentralización, el contexto internacional y el proceso de apertura comercial.

No obstante la pérdida de dinamismo en esta región, el sector continúa como uno de los más importantes para las cuatro entidades federativas. En el Estado de México aún se encuentra un número muy importante de unidades económicas automotrices, $10 \%$ del total nacional, que generan $9.8 \%$ del valor agregado y emplean a $6.2 \%$ de la población nacional ocupada en el sector. Más que de ensambladoras, se destaca la presencia de empresas productoras de partes de primer, segundo y tercer nivel.

Todo indica que en esta entidad se ha iniciado un proceso de reconversión de la industria automotriz ante el agotamiento de procesos productivos. En 2010, la planta de Ford, en Cuautitlán, Estado de México, fue desmantelada en su totalidad y reconstruida con todos los requerimientos tecnológicos actuales, lo que le permite manufacturar el modelo Ford Fiesta híbrido para todo el mundo. La planta de Chrysler localizada en Toluca, por su parte, ha tomado un nuevo 
auge en el ensamble de vehículos derivado de la fusión con Fiat, en 2014, para conformar lo que ahora se llama Fiat Chrysler Automóviles.

En el caso de la Ciudad de México, prácticamente han desaparecido las actividades de ensamble de vehículos; lo que destaca es la presencia de las oficinas de los grandes corporativos del sector y de algunas productoras de partes $\mathrm{y}$ componentes que han sobrevivido a este proceso. Además, en estas dos entidades se encuentran importantes instalaciones de investigación y desarrollo (ID), incluido el diseño de partes, como es el caso de Chrysler y Ford, en la Ciudad de México, y de General Motors, en Toluca, Estado de México.

Cuadro 1. México: región Centro, sector automotriz, principales variables, 1980-2014 (participación porcentual)

\begin{tabular}{|c|c|c|c|c|c|c|c|c|c|c|c|c|c|c|c|}
\hline & \multicolumn{5}{|c|}{ Unidades económicas } & \multicolumn{5}{|c|}{ Valor agregado censal bruto } & \multicolumn{5}{|c|}{ Población ocupada } \\
\hline & 1980 & 1989 & 1999 & 2009 & 2014 & 1980 & 1989 & 1999 & 2009 & 2014 & 1980 & 1989 & 1999 & 2009 & 2014 \\
\hline $\begin{array}{l}\text { Región } \\
\text { Centro }\end{array}$ & 48.6 & 43.1 & 34.5 & 24.9 & 26.6 & 78.7 & 47.6 & 25.3 & 27.3 & 28.8 & 63.7 & 37.7 & 21.0 & 19.0 & 14.4 \\
\hline $\begin{array}{l}\text { Ciudad } \\
\text { de México }\end{array}$ & 31.9 & 23.9 & 16.2 & 8.9 & 7.1 & 29.7 & 6.1 & -4.3 & 0.9 & 0.1 & 23.2 & 11.0 & 3.4 & 2.4 & 1.8 \\
\hline $\begin{array}{l}\text { Estado } \\
\text { de México }\end{array}$ & 12.2 & 15.0 & 15.4 & 11.5 & 10.0 & 32.9 & 19.0 & 15.9 & 10.3 & 9.8 & 28.2 & 18.4 & 10.6 & 8.7 & 6.2 \\
\hline Morelos & 0.9 & 0.9 & 0.6 & 0.0 & 0.4 & 3.6 & 16.3 & 2.7 & 1.5 & 2.5 & 2.5 & 2.1 & 0.6 & 0.8 & 1.0 \\
\hline Puebla & 3.6 & 3.3 & 2.3 & 4.6 & 9.0 & 12.5 & 6.3 & 11.0 & 14.7 & 16.4 & 9.9 & 6.2 & 6.3 & 7.2 & 5.5 \\
\hline
\end{tabular}

Fuente: elaboración propia con datos de INEGI (1980; 1989; 1999; 2009; 2014b).

La situación ha sido diferente para las otras dos entidades que conforman esta región. En el caso de Puebla, se ha incrementado de manera significativa su participación dentro del sector automotriz, principalmente porque en esta entidad se localiza una planta de Volkswagen, que es hoy la segunda más importante del mundo ${ }^{5}$ y que ha servido para dinamizar de manera significativa la actividad económica de la región.

La participación de Puebla dentro del sector se ha consolidado y es evidente el incremento en las variables de análisis a lo largo del periodo de estudio. En 2014, concentró $9.0 \%$ de las unidades económicas, $16.4 \%$ del vaCB y $5.5 \%$ de la PO en el sector (cuadro 1). Además, la próxima apertura de la planta de Audi en San José Chiapa, Puebla, sin duda, dinamizará aún más al sector en esta enti-

\footnotetext{
${ }^{5}$ Esta planta ensambla los modelos Beetle, Jetta Clásico, Jetta Clásico TDI, Nuevo Jetta y Golf.
} 
dad y en la región. El estado de Morelos, por su parte, cuenta con la presencia de Nissan en la ciudad de Cuautla, donde se producen vehículos tipo pick up, como el Frontier L4, así como los modelos Tsuru y Tidda, y que, de igual forma, ha venido a impulsar de manera importante la actividad económica de la zona.

Por otro lado se encuentra la región Norte o fronteriza, conformada por Baja California, Sonora, Chihuahua, Coahuila, Nuevo León y Tamaulipas. En estas entidades federativas, desde finales de los setenta y principios de los ochenta, se empezaron a establecer importantes complejos automotrices conformados por ensambladoras y, posteriormente, empresas proveedoras de partes, como resultado de los factores externos e internos ya comentados. Actualmente se ha convertido en la región más dinámica y competitiva del sector, llegando a conformar un importante conglomerado regional (Unger, 2003; 2010; Unger y Chico, 2004).

La participación porcentual de estas entidades en la industria automotriz nacional ha crecido sustancialmente, al igual que la de la región en su conjunto. El incremento más importante se ha dado en VACB y PO, pues tuvieron en este periodo un aumento superior a $42 \%$. En 2014, las entidades federativas que conforman esta región generaron $50.8 \%$ del total del valor agregado del ramo automotriz a nivel nacional y emplearon a $58.8 \%$ del total de la PO; además, en esta región se concentra $33.0 \%$ de las unidades económicas del sector (cuadro 2).

En este crecimiento tan importante ha sido fundamental el rol de Chihuahua, Coahuila y Sonora. ${ }^{6}$ Sólo por mencionar algunos datos, de 1980 a 2014 , la PO en la industria automotriz en Chihuahua pasó de 3200 a 123283 personas; en Coahuila, de 2635 a 124 634, y en Sonora, de 401 a 39 523, lo que representa participaciones en el total nacional de $17.1 \%, 17.3 \%$ y $5.5 \%$, en 2014 , respectivamente. Las entidades que integran esta región se caracterizan, además, por haber recibido durante el periodo estudiado un importante número de empresas de autopartes, que, siguiendo a las armadoras, han llegado a establecerse en la región, conformando un importante conglomerado automotriz.

Otra región en la que el sector ha tenido un crecimiento muy destacado, sobre todo en los años más recientes, es la Centro-Norte, integrada por San Luis Potosí, Querétaro y Guanajuato. La presencia de armadoras como General Motors y Volkswagen, en Silao, Guanajuato, y General Motors, en San Luis Potosí, ha generado una importante dinámica regional, con un incremento sustancial de productoras de partes tanto de primer nivel, como de segundo y tercero. Es el

\footnotetext{
${ }^{6}$ Chihuahua, con Ford a la cabeza; Coahuila, con General Motors en Ramos Arizpe y Chrysler en Saltillo, y Sonora, con Ford en Hermosillo.
} 
Cuadro 2. México: región Norte, sector automotriz, principales variables, 1980-2014 (participación porcentual)

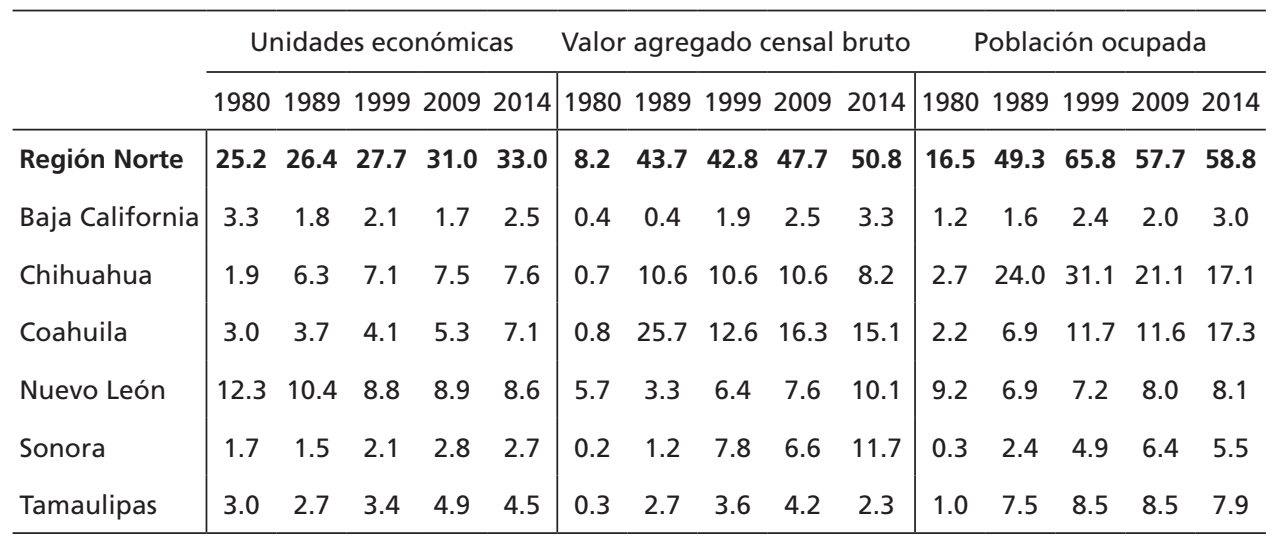

Fuente: Elaboración propia con datos de INEGI (1980, 1989, 1999, 2009 y 2014b).

caso de Querétaro, donde se localizan sesenta proveedores de partes de primer nivel y más de doscientas de segundo y tercero, con lo que se ha convertido en un importante centro de proveeduría a nivel nacional (Becerril, 2013).

La participación de esta región en la industria automotriz nacional se ha incrementado notablemente. Para 2014 concentró $13.2 \%$ del total de las unidades económicas, las cuales generaron $12.2 \%$ del $\mathrm{vACB}$ y emplearon $14.6 \%$ de la Po del sector nacional (cuadro 3). Sin duda, esta región continuará en ascenso por el efecto de la instalación de dos nuevas plantas armadoras: Mazda, con una

Cuadro 3. México: región Centro-Norte, sector automotriz, principales variables, 1980-2014

(participación porcentual)

\begin{tabular}{|c|c|c|c|c|c|c|c|c|c|c|c|c|c|c|c|}
\hline & & nidad & es eco & nómi & cas & & lor ag & $\begin{array}{l}\text { yregad } \\
\text { bruto }\end{array}$ & do cen & & & Poblaci & ción o & cupad & \\
\hline & 1980 & 1989 & 1999 & 2009 & 2014 & 1980 & 1989 & 1999 & 2009 & 2014 & 1980 & 1989 & 1999 & 2009 & 2014 \\
\hline $\begin{array}{l}\text { Región } \\
\text { Centro-Norte }\end{array}$ & 3.2 & 6.3 & 6.3 & 10.1 & 13.2 & 0.3 & 5.5 & 23.8 & 13.6 & 12.2 & 0.8 & 6.2 & 5.4 & 12.6 & 14.6 \\
\hline Guanajuato & 1.6 & 2.2 & 1.5 & 2.1 & 5.6 & 0.2 & 1.8 & 18.3 & 6.3 & 6.2 & 0.4 & 1.8 & 2.5 & 3.8 & 5.6 \\
\hline Querétaro & 0.3 & 2.1 & 2.4 & 4.3 & 4.7 & 0.0 & 2.9 & 4.2 & 4.6 & 2.3 & 0.1 & 3.2 & 2.2 & 4.6 & 4.7 \\
\hline San Luis Potosí & 1.3 & 2.0 & 2.3 & 3.7 & 2.8 & 0.1 & 0.8 & 1.3 & 2.6 & 3.7 & 0.3 & 1.2 & 0.8 & 4.2 & 4.3 \\
\hline
\end{tabular}

Fuente: Elaboración propia con datos de INEGI (1980, 1989, 1999, 2009 y 2014b). 
Cuadro 4. México: región Occidente, sector automotriz, principales variables, 1980-2014

(participación porcentual)

\begin{tabular}{|c|c|c|c|c|c|c|c|c|c|c|c|c|c|c|c|}
\hline & & hidade & es eco & nóm & & & or ag & $\begin{array}{l}\text { rega } \\
\text { brutc }\end{array}$ & do ce & & & oblac & ión c & cupa & \\
\hline & 1980 & 1989 & 1999 & 200 & 2014 & 1980 & 1989 & 1999 & 2009 & 2014 & 1980 & 1989 & 199 & 2009 & 2014 \\
\hline $\begin{array}{l}\text { Región } \\
\text { Occidente }\end{array}$ & 9.7 & 11.1 & 11.0 & 9.7 & 8.8 & 1.5 & 1.5 & 6.5 & 9.6 & 6.0 & 3.4 & 3.3 & 4.9 & 5.2 & 4.9 \\
\hline Aguascalientes & 1.0 & 1.4 & 1.6 & 2.2 & 2.2 & 0.1 & 0.9 & 5.3 & 7.7 & 4.1 & 0.2 & 1.6 & 2.7 & 3.0 & 3.3 \\
\hline Jalisco & 8.7 & 9.7 & 9.4 & 7.4 & 6.6 & 1.5 & 0.6 & 1.2 & 1.9 & 1.9 & 3.1 & 1.7 & 2.2 & 2.2 & 1.6 \\
\hline
\end{tabular}

Fuente: Elaboración propia con datos de INEGI (1980, 1989, 1999, 2009 y 2014b).

inversión de USD 500 millones, en Salamanca, y Honda, con USD 800 millones invertidos en una planta de ensamble en Celaya, Guanajuato.

Finalmente, la industria automotriz en la región Occidente, conformada por los estados de Jalisco y Aguascalientes, a pesar de que no ha tenido crecimientos espectaculares, sí ha tenido una evolución constante y progresiva, sobre todo a partir del establecimiento de la planta de ensamble de Honda en El Salto, Jalisco, y una de motores y otra de ensamble, de Nissan, en Aguascalientes. A partir de ello se ha estimulado también el establecimiento de proveedores de partes de primer y segundo nivel. La aportación que esta región hace al sector automotriz nacional actualmente es de $8.8 \%$ en unidades económicas, $6.0 \%$ del VACB y $4.9 \%$ de la Po (cuadro 4 ).

Es importante hacer notar que esta región tiene un gran potencial para crecer en términos del sector, sobre todo por la cercanía que tiene con los estados de Guanajuato, Querétaro y San Luis Potosí. Se están realizando esfuerzos importantes por parte de las autoridades ${ }^{7} \mathrm{y}$ del sector empresarial para atraer inversiones que permitan consolidar la participación de Jalisco en el corredor automotriz del Bajío.

En Aguascalientes, sin duda, el sector automotriz es uno de los más representativos de su economía. Genera 35.3\% del PIB estatal, $80.4 \%$ de la IED se ha destinado a ese sector y participa con $75.9 \%$ de las exportaciones totales de la entidad. Entre las inversiones recientes destaca la construcción del Parque Indus-

\footnotetext{
${ }^{7}$ Se amplió la carretera León-Lagos de Moreno (Ortega, 2015) y se tiene el proyecto de un nuevo parque industrial en Jalisco (s.a., 2016).
} 
trial de Logística Automotriz (PILA), que ya se encuentra en operación, y cuyo fin es el establecimiento de empresas proveedoras del sector automotriz (Secretaría del Desarrollo Económico, 2016). También, el inicio de operaciones, en septiembre de 2014, de la segunda planta en México de Jatco Limited, compañía dedicada a la fabricación de autopartes, con una inversión de más de USD 220 millones (González, 2014).

\section{EL SECTOR AUTOMOTRIZ Y EL CRECIMIENTO DE LA MANUFACTURA EN CUATRO REgIONES DE MÉXICO}

Como señala Thirlwall (2003), no todos los sectores económicos son iguales, existen unos más importantes que otros y el crecimiento agregado está relacionado con aquel cuya actividad posee características más favorables para su expansión. En este sentido, la manufactura puede ser el motor del crecimiento económico de un país o región por las posibilidades de desarrollar encadenamientos productivos hacia atrás y hacia delante en las diferentes ramas de actividad. Sobre todo si dentro del sector hay una participación destacada de algunos subsectores que tienen mayor dinamismo que otros y, por ello, pueden ser estratégicos para el crecimiento de la manufactura y de la actividad económica, en general, de las regiones donde se localizan. ${ }^{8}$ Este es el caso de la industria automotriz, dadas sus características de producción, contenido tecnológico y productividad.

El propósito de este apartado es presentar evidencia de que la industria automotriz ha jugado un papel muy importante en el florecimiento de la manufactura de las entidades federativas de México y, en general, de las regiones donde se localiza. Se trata de demostrar que las entidades con un mayor crecimiento de este sector también son las que han experimentado incrementos manufactureros más significativos y que existe una relación de causalidad importante entre ambos ramos.

En un acercamiento diagnóstico a esta relación se observan algunas regularidades importantes. Al comparar las tasas de crecimiento del PIB real del sector automotriz y del manufacturero durante 1994-2014 (gráfica 1) y las de la respectiva PO durante $1994-2008^{9}$ (gráfica 2), se observa que el automotriz pre-

\footnotetext{
${ }^{8}$ Rendón-Rojas y Mejía (2015) proporcionan evidencia de que el crecimiento de la manufactura en el Estado de México se explica por los sectores 35 Sustancias químicas, productos derivados del petróleo y del carbón, hule y de plástico, y 38 Productos metálicos, maquinaria y equipo.

${ }^{9}$ Los datos de Po en la manufactura y en la industria automotriz a partir de 2008 presentan diferencias importantes aun siendo la misma fuente, por lo cual no se actualizaron.
} 
Gráfica 1. México: PIB de la manufactura y del sector automotriz, 1994-2014 (tasas de crecimiento porcentual)

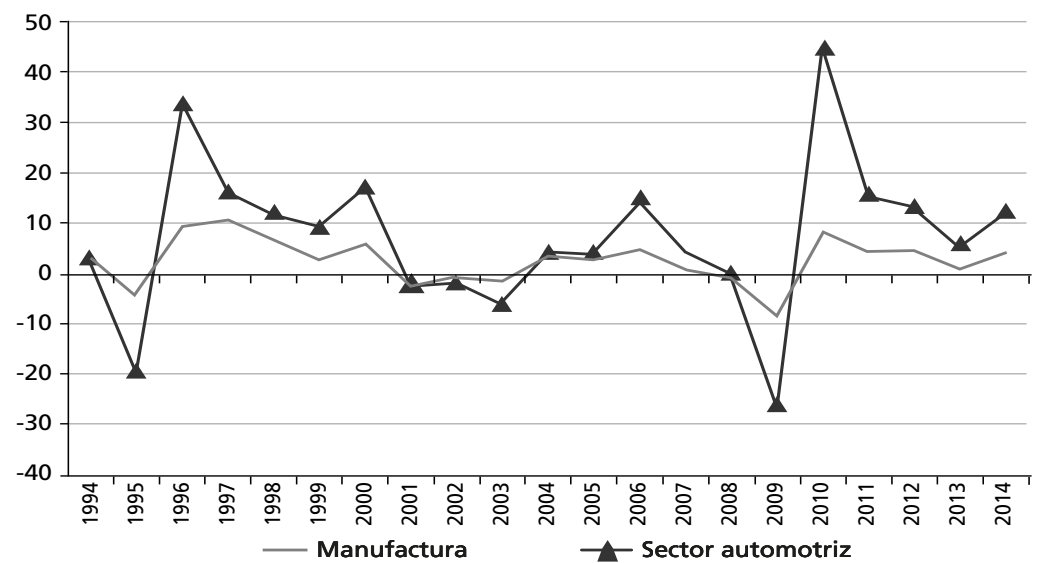

Fuente: INEGI (2014a).

senta fluctuaciones mayores. Sus tasas de crecimiento han sido superiores a las de la manufactura y deja ver un sector más sensible a los impactos que experimenta la economía, de modo que en periodos de crisis sus caídas son más pronunciadas y en los de recuperación su expansión es más intensa. Este comportamiento se explica por su elevada sensibilidad a la demanda, dado el carácter duradero de los bienes de esta industria. Más aún, se puede observar una correlación importante entre el crecimiento de la producción de ambos sectores y el del empleo, ${ }^{10}$ lo que permite suponer que el sector automotriz está impulsando el crecimiento de la manufactura.

De acuerdo con las gráficas 1 y 2 , se podría argumentar que hay una relación muy importante entre la evolución de la manufactura y la de la industria automotriz, lo que permitiría suponer que la producción de ésta incide en el crecimiento manufacturero. Aun cuando esta relación causal pueda ser cuestionable, este trabajo abona a favor de tal hipótesis, ya que al menos las pruebas de causalidad en el sentido de Granger ${ }^{11}$ dejan ver esta posibilidad. Los datos agre-

${ }^{10}$ La correlación entre las tasas de crecimiento del PIB de la manufactura y el del sector automotriz es de 0.906 durante el periodo 1994-2014, mientras la correlación entre las respectivas tasas de crecimiento del empleo, en el mismo lapso, es de 0.897 .

${ }^{11}$ Recuérdese que la noción de causalidad en sentido de Granger (1969) es una prueba para evaluar si existe precedencia estadística del pasado de una variable respecto a otra y, por lo tanto, contribuye a explicarla. 
Gráfica 2. México: población ocupada en la manufactura y en el sector automotriz, 1995-2008

(tasas anualizadas de crecimiento porcentual)

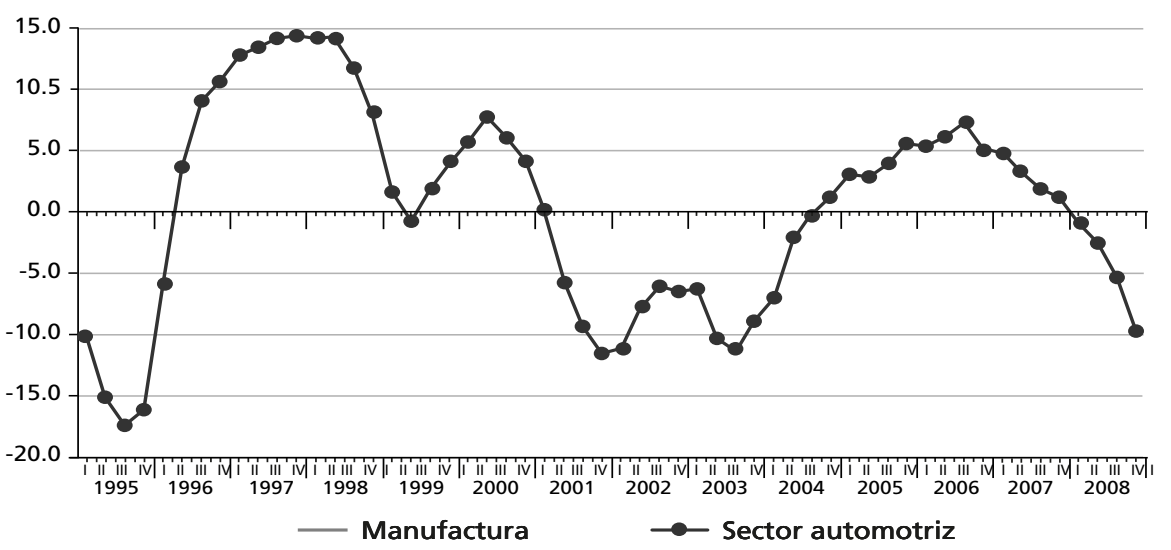

Fuente: INEGI (2014a).

gados de la producción manufacturera y del sector automotriz en México durante el periodo 1994-2014 (cuadro 5) aportan evidencia de que el PIB del sector automotriz causa, en el sentido de Granger, al PIB manufacturero.

En el caso de las regiones, y de acuerdo con la información del cuadro 6, se puede observar que la participación de la industria automotriz en la manufactura se ha incrementado de manera notable en los últimos treinta años. En 1980, la industria automotriz aportaba $9.5 \%$ del vACB total de la manufactura nacional, participación que se incrementó a $20.9 \%$ para 2014; la aportación del sector a la PO en la manufactura aumentó de $5.6 \%$ a $14.2 \%$ en el mismo periodo. El crecimiento regional y el experimentado por entidad federativa han sido diferenciados, como se evidenció en el apartado anterior, sin embargo, es claro que la aportación que hace el sector automotriz a la manufactura en ambos casos es cada vez es más importante.

La región Centro es donde el sector automotriz ha presentado los incrementos más moderados en su aportación a la manufactura, mientras que las otras tres regiones han tenido crecimientos mucho más significativos. En la región Centro-Norte, esta industria aportaba sólo $0.7 \%$ del VACB de la manufactura y 0.7\% del Po en 1980, pero en 2014 su aportación llegó a 21.7\% y 16.6\%, respectivamente. Por otra parte, en la región Norte también ha incrementado sustancialmente sus aportaciones a la manufactura, hasta llegar a contribuir con $29.9 \%$ 
Cuadro 5. México: PIB real de la manufactura y del sector automotriz.

Pruebas de causalidad, 1994.I-2014.IV

(primeras diferencias)

\begin{tabular}{|c|c|c|c|}
\hline & Rezagos & Estadístico $F$ & Probabilidad \\
\hline$\Delta / y_{\operatorname{man}}$ no causa a $\Delta / y_{\text {auto }}$ & 1 & 0.080 & 0.777 \\
\hline$\Delta / y_{\text {auto }}$ no causa a $\Delta / y_{\operatorname{man}}$ & 1 & 3.983 & 0.049 \\
\hline$\Delta / y_{\operatorname{man}}$ no causa a $\Delta / y_{\text {auto }}$ & 2 & 0.132 & 0.876 \\
\hline$\Delta / y_{\text {auto }}$ no causa a $\Delta / y_{\operatorname{man}}$ & 2 & 2.403 & 0.096 \\
\hline$\Delta / y_{\operatorname{man}}$ no causa a $\Delta / y_{\text {auto }}$ & 3 & 0.007 & 0.999 \\
\hline$\Delta / y_{\text {auto }}$ no causa a $\Delta / y_{\operatorname{man}}$ & 3 & 2.338 & 0.080 \\
\hline$\Delta / y_{\operatorname{man}}$ no causa a $\Delta / y_{\text {auto }}$ & 4 & 0.051 & 0.994 \\
\hline$\Delta / y_{\text {auto }}$ no causa a $\Delta / y_{\operatorname{man}}$ & 4 & 3.208 & 0.017 \\
\hline
\end{tabular}

Nota: Se aplicaron las pruebas de causalidad en el sentido de Granger con datos trimestrales para el periodo 1994.I-2014.IV. Son datos reales del producto interno bruto de la manufactura $\left(P I B_{\operatorname{man}}\right)$ y de la industria automotriz $\left(y_{\text {auto }}\right)$, a precios de 2008 . Para evitar algún efecto de composición de la serie, al PIB manufacturero $\left(P I B_{\operatorname{man}}\right)$ se le restó, primero, el valor del PIB de la industria automotriz, por lo que al producto manufacturero, sin el valor del PIB del sector automotriz, se le denomina $y_{\operatorname{man}}=P I B_{\operatorname{man}}-y_{\text {auto }}$. Siguiendo la metodología estándar, se evaluó causalidad de uno a cuatro rezagos, en primeras diferencias del logaritmo.

Fuente: Estimaciones realizadas con datos del INEGI (2015).

del VACB y $23.3 \%$ del total de la Po en manufactura, en 2014. No obstante, el incremento más importante ha sido la aportación del sector automotriz al VACB manufacturero de la región Occidente (cuadro 6).

El análisis por entidad federativa arroja datos reveladores. Por ejemplo, el hecho de que en Aguascalientes (región Occidente) y Puebla (región Centro), el sector automotriz se ha convertido en el más dinámico no sólo de la manufactura, sino de la actividad económica global de esas entidades. En Aguascalientes, la industria automotriz aporta $57.3 \%$ del VACB manufacturero del estado y emplea a $27.0 \%$ del total de la PO. En Puebla, el sector automotriz aporta a la manufactura $63.2 \%$ del VACB y $16.7 \%$ de la PO. Como se puede observar, la contribución al sector manufacturero es muy relevante en prácticamente todos los estados analizados, lo que sin duda respalda el planteamiento del que partió este trabajo, en el sentido de que el sector automotriz ha impulsado a la manufactura en las cuatro diferentes regiones donde se concentra.

Como se ha explicado, hay una relación muy estrecha entre el crecimiento de la producción de la manufactura y el de la industria automotriz, por lo que no resulta extraño que en las entidades federativas en las que se ha instalado 
Cuadro 6. México: Participación porcentual del sector automotriz en el total de la manufactura nacional, por región y por entidad federativa, 1980-2014

\begin{tabular}{|c|c|c|c|c|c|c|c|c|c|c|c|c|c|c|c|}
\hline & \multicolumn{5}{|c|}{ Unidades económicas } & \multicolumn{5}{|c|}{$\begin{array}{l}\text { Valor agregado censal } \\
\text { bruto }\end{array}$} & \multicolumn{5}{|c|}{ Población ocupada } \\
\hline & 1980 & 1989 & 1999 & 2009 & 2014 & 1980 & 1989 & 1999 & 2009 & 2014 & 1980 & 1989 & 1999 & 2009 & 2014 \\
\hline Nacional & 0.8 & 0.7 & 0.6 & 0.5 & 0.4 & 9.5 & 13.6 & 14.3 & 14.4 & 20.9 & 5.6 & 7.9 & 10.0 & 11.0 & 14.2 \\
\hline Región Centro & 0.9 & 0.9 & 0.7 & 0.4 & 0.4 & 13.0 & 14.6 & 10.9 & 14.1 & 24.1 & 7.2 & 7.7 & 7.2 & 8.0 & 8.8 \\
\hline Distrito Federal & 1.1 & 1.1 & 1.1 & 0.6 & 0.5 & 9.6 & 4.1 & -5.9 & 1.5 & 0.3 & 4.7 & 4.6 & 3.0 & 3.0 & 3.5 \\
\hline Estado de México & 1.1 & 1.2 & 0.9 & 0.5 & 0.4 & 13.7 & 14.2 & 13.4 & 11.0 & 17.5 & 9.5 & 10.1 & 9.2 & 8.4 & 8.3 \\
\hline Morelos & 0.5 & 0.5 & 0.2 & 0.0 & 0.1 & 28.0 & 69.7 & 25.0 & 17.9 & 43.4 & 14.0 & 14.9 & 6.7 & 7.8 & 13.2 \\
\hline Puebla & 0.4 & 0.3 & 0.2 & 0.2 & 0.5 & 29.2 & 28.2 & 37.2 & 47.7 & 63.2 & 13.7 & 11.9 & 11.8 & 15.6 & 16.7 \\
\hline $\begin{array}{l}\text { Región } \\
\text { Centro-Norte }\end{array}$ & 0.3 & 0.5 & 0.4 & 0.5 & 0.6 & 0.7 & 8.3 & 28.9 & 17.8 & 21.7 & 0.7 & 5.9 & 5.8 & 13.0 & 16.6 \\
\hline Guanajuato & 0.3 & 0.3 & 0.1 & 0.2 & 0.4 & 3.3 & 5.4 & 46.3 & 17.8 & 22.3 & 0.8 & 3.2 & 4.5 & 7.3 & 11.7 \\
\hline Querétaro & 0.3 & 1.5 & 1.2 & 1.4 & 1.5 & 0.2 & 17.9 & 17.2 & 20.2 & 15.8 & 0.3 & 13.7 & 10.3 & 19.6 & 20.6 \\
\hline San Luis Potosí & 0.5 & 0.6 & 0.7 & 0.9 & 0.7 & 0.5 & 4.9 & 7.1 & 14.7 & 26.4 & 1.2 & 4.7 & 4.4 & 20.1 & 24.8 \\
\hline Región Norte & 1.5 & 1.3 & 1.2 & 1.2 & 1.3 & $4 . .2$ & 22.8 & 19.8 & 20.9 & 29.9 & 4.4 & 14.1 & 19.3 & 18.7 & 23.3 \\
\hline Baja California & 1.6 & 0.9 & 0.9 & 0.6 & 0.7 & 2.5 & 3.4 & 6.6 & 8.7 & 18.0 & 3.2 & 4.3 & 4.0 & 3.7 & 6.7 \\
\hline Chihuahua & 0.7 & 1.7 & 1.7 & 1.9 & 1.9 & 4.0 & 40.5 & 31.2 & 30.3 & 40.7 & 5.1 & 29.2 & 37.1 & 31.3 & 32.9 \\
\hline Coahuila & 1.4 & 1.2 & 1.2 & 1.3 & 1.9 & 2.6 & 54.5 & 30.2 & 36.7 & 39.1 & 4.4 & 13.3 & 26.0 & 29.4 & 42.6 \\
\hline Nuevo León & 2.2 & 1.7 & 1.4 & 1.4 & 1.4 & 5.1 & 4.4 & 9.6 & 11.1 & 20.5 & 5.7 & 7.0 & 9.4 & 11.5 & 13.8 \\
\hline Sonora & 0.8 & 0.6 & 0.7 & 0.6 & 0.5 & 1.6 & 8.6 & 33.6 & 26.5 & 48.3 & 1.0 & 7.6 & 15.3 & 20.6 & 22.5 \\
\hline Tamaulipas & 1.3 & 0.9 & 1.0 & 1.1 & 1.2 & 6.8 & 14.5 & 16.0 & 15.2 & 12.2 & 2.6 & 15.8 & 18.9 & 18.6 & 24.5 \\
\hline $\begin{array}{l}\text { Región } \\
\text { Occidente }\end{array}$ & 0.9 & 0.9 & 0.7 & 0.6 & 0.5 & 2.1 & 3.1 & 9.4 & 15.9 & 14.1 & 2.4 & 3.3 & 5.3 & 5.9 & 7.4 \\
\hline Aguascalientes & 0.8 & 0.9 & 0.9 & 1.1 & 1.0 & 1.4 & 20.5 & 47.2 & 61.9 & 57.3 & 1.5 & 9.6 & 16.6 & 21.1 & 27.0 \\
\hline Jalisco & 0.9 & 1.0 & 0.7 & 0.5 & 0.4 & 2.1 & 1.3 & 2.1 & 4.0 & 5.3 & 2.5 & 2.0 & 2.8 & 3.0 & 3.0 \\
\hline
\end{tabular}

Fuente: elaboración propia con datos de INEGI (1980, 1989, 1999, 2009 y 2014b).

el sector automotriz también ha crecido de manera importante la industria manufacturera. Con el propósito de aportar evidencia empírica que respalde esta descripción, en el siguiente apartado se estima un modelo de panel del crecimiento de la producción de la manufactura en el que se incluye el incremento de la producción de la industria automotriz como una variable exógena importante, de acuerdo con lo que se ha discutido.

\section{UN MODELO DE PANEL DEL CRECIMIENTO DE LA MANUFACTURA}

Se integró un panel de datos con estadísticas censales de los años 1985, 1988, 1993, 1998, 2003, 2008 y 2013. Esta información oficial fue publicada por el Instituto Nacional de Estadística y Geografía (INEGI, 1986; 1989; 1994; 1999; 
$2004 ; 2009 ; 2014 b$ ), con datos reales a precios de 2003. El crecimiento de la manufactura se expresa en términos de un modelo general de regresión lineal con datos de panel en los siguientes términos:

$$
y_{i t}^{m}=\alpha_{i}+\alpha_{1} y_{i t}^{\text {auto }}+v_{i t} \text {, }
$$

donde $y_{i t}^{m}$ es la tasa de crecimiento del producto manufacturero, $y_{i t}^{\text {auto }}$ es la tasa de crecimiento del sector automotriz y $v_{i t}$ es un término de perturbación, para $i=1, \ldots N$ unidades; $t=1, \ldots T$ periodos.

Para la estimación de (2), y con el fin de evitar efectos de composición de la serie, al producto manufacturero se le restó el producto de la industria automotriz. ${ }^{12}$ De esta forma, es la tasa de crecimiento del producto manufacturero sin incluir la producción automotriz. La ecuación (2) es una analogía de la primera ley de Kaldor en el sentido de que se considera al sector automotriz como el más dinámico, caracterizado por generar economías de escala, externalidades e innovación, lo que puede convertirlo en el motor de crecimiento de la manufactura.

En este sentido, se extendió (2) con el propósito de estimar tres modelos que midan tanto el efecto de la productividad $\left(y l_{\text {man }}\right)$, a partir del argumento de que el aumento continuo de ésta es un factor fundamental para alcanzar incrementos sostenidos en la producción -además de que en el contexto actual de apertura se propone que se puede detonar un círculo virtuoso que provoque aumentos en la productividad al incentivar la competencia doméstica y facilitar la transferencia tecnológica (Fragoso, 2003)-, como el efecto de la producción de Estados Unidos $\left(y_{E U}\right)$ por la estrecha correlación que la manufactura tiene con la economía de ese país (Castillo, Díaz y Fragoso, 2004; Chiquiar y Ramos-Francia, 2005; Mejía y Campos-Chávez, 2009) y porque es un indicador que refleja de algún modo los efectos del proceso de apertura comercial por la dinámica de su relación de intercambio con México.

Finalmente, los niveles de inversión $\left(k^{\text {auto }}\right)$ se miden por la formación bruta de capital en el sector. El caso de la inversión es importante porque se asocia con efectos favorables en el crecimiento de la actividad económica. Su inclusión se debe al argumento keynesiano de que el gasto en inversión genera mayor demanda agregada, disminución en inventarios y aumento de la ocupación, además de propiciar un incremento en la capacidad productiva sectorial (Lechuga y Varela, 2001). En el contexto reciente de México son diversos los estudios que

\footnotetext{
${ }^{12}$ Dado que la producción automotriz está contenida en la de la industria manufacturera.
} 
refieren que los problemas de crecimiento del país se explican por la baja tasa de inversión (Ros, 2008; Ibarra, 2008). Se considera, entonces, la ampliación de la primera ley de Kaldor, expresada en la ecuación (2), de la siguiente forma:

$$
\begin{gathered}
y_{i t}{ }^{m}=\alpha_{i}+\alpha_{1} y_{i t}{ }^{\text {auto }}+y_{t}^{E U}+y \operatorname{lman}_{i t}+v_{i t} \\
y_{i t}{ }^{m}=\alpha_{i}+\alpha_{1} y_{i t}{ }^{a u t o}+y^{E U} t+y \operatorname{lman}_{i t}+k_{i t}{ }^{\text {auto }}+v_{i t},
\end{gathered}
$$

donde $y_{i t}^{m}$ es la tasa de crecimiento del VACB manufacturero, sin incluir el de la industria automotriz, $y^{\text {auto }}$ es la tasa de crecimiento del VACB de la industria automotriz; $y_{E U}$, el PIB industrial de Estados Unidos; $y l_{\text {man }}$, el producto medio del trabajo de la manufactura, $y k^{\text {auto }}$, la inversión en el sector, medida por la formación bruta de capital en el sector automotriz. Finalmente, $v_{\text {it }}$ es un término de perturbación para $i=1, \ldots N$ unidades; $t=1, \ldots T$ periodos.

Se consideró la técnica de datos de panel dada la estructura que tiene la información estadística disponible sobre manufactura e industria automotriz en las entidades federativas de México que conforman las regiones de análisis. Además, porque los datos de panel permiten identificar y medir algunos efectos que no pueden considerarse al utilizar únicamente datos de corte transversal o datos de series temporales; asimismo, posibilitan tener en cuenta la existencia de efectos individuales inobservables que pueden estar correlacionados con otras variables incluidas en la especificación de una relación econométrica (Hsiao, 2003).

\section{Discusión de los resultados}

En principio, cada uno de los modelos 1, 2 y 3 -que corrresponden a las ecuaciones (2) (3) y (4)- se estimó con la técnica de datos agrupados, la de efectos fijos y la de efectos aleatorios. ${ }^{13}$ Se aplicó la prueba de datos agrupados (pool test) y la

${ }^{13}$ Primero se comparó el modelo de efectos fijos con el modelo de datos agrupados para evaluar la eficiencia del primero. Para ello, la prueba de datos agrupados utiliza una prueba de restricción de parámetros entre los dos modelos y se analizan las hipótesis:

$\mathrm{H}_{0}: \forall \mu_{i}=0$

$\mathrm{H}_{1}: \mu_{1} \neq 0, \ldots, \mu_{i} \neq 0$

$\mathrm{Si}$ la hipótesis nula $\mathrm{H}_{0}$ no se puede rechazar, se opta por el modelo de datos agrupados; en caso contrario, se elige el de efectos fijos. Para decidir entre un modelo de efectos fijos o uno de efectos aleatorios se utilizó la prueba de Hausman, como lo explican Reyes, Rendón-Rojas y Mejía, (2016), que contrasta las estimaciones de ambos modelos. Si se encuentran diferencias significativas, se rechaza la hipótesis nula de igualdad debido a que, asumiendo una especificación razona- 
de Hausman para evaluar y elegir el mejor modelo y se concluyó que el modelo de datos agrupados es consistente con efectos fijos, por lo que no era necesario estimar los modelos con efectos aleatorios. Los resultados de las pruebas arrojaron valores del estadístico $F$ con probabilidades mayores a 0.05 (cuadro 7).

De acuerdo con los resultados de las estimaciones, se puede notar lo siguiente: el modelo 1 (primera ley de Kaldor) deja ver una correlación positiva entre el crecimiento de la producción de la industria automotriz $\left(y^{\text {auto }}\right)$ y el crecimiento de la manufactura $\left(y^{m}\right)$. Además, por los resultados del modelo 2 , se puede argumentar que la correlación que la economía mexicana, específicamente la manufactura, tiene con la de Estados Unidos $\left(y_{E U}\right)$ es muy importante (coeficiente de 0.293 ). Pero, sobre todo, destaca el significativo peso que tiene la producti$\operatorname{vidad}\left(\mathrm{yl}_{\text {man }}\right)$ (coeficiente entre 0.918 y 0.919 ), de acuerdo con los modelos 2 y 3. Dada la probabilidad del estadístico $t$, los coeficientes de $y^{\text {auto }}$ son robustos en los tres modelos; para $y_{E U}$, se registra un efecto positivo y significativo a $95 \%$; para $y l_{\text {man }}$, los coeficientes son robustos a $100 \%$.

Estos resultados se pueden explicar por el hecho de que alrededor de $80 \%$ de las exportaciones mexicanas se realizan a Estados Unidos, de ahí que exista una relación muy estrecha; además de que hay evidencia de que "[...] la economía mexicana desde 1988 se ha especializado de manera creciente en actividades exportadoras e intensivas en capital" (Dussel, 2003, p.148) y de que la manufactura proporciona actualmente poco más de $85 \%$ de las exportaciones totales de México (Moreno-Brid, Santamaría y Rivas, 2006). Sin embargo, aun cuando el coeficiente de la producción automotriz $\left(y^{\text {auto }}\right)$ es relativamente bajo (entre 0.024 y 0.049), no debe dejarse de lado el hecho de que el desarrollo exportador de México no se extendió uniformemente a todas y cada una de las industrias manufactureras del país; por el contrario, se tuvo una alta concentración. Algunas ramas, como las de motores y partes automotrices, automóviles, computación y equipo electrónico diverso, explican 58\% de las exportaciones manufactureras totales de México entre 1994 y 2003 (Moreno-Brid, Santamaría y Rivas, 2006). En consecuencia, se puede argumentar que la industria automotriz es un sector de gran impulso para el crecimiento de la producción manufacturera.

Finalmente, aunque $k^{\text {auto }}$ es positivo, como sugiere la clara relación que existe entre la inversión y el producto, no resulta significativo. El resultado del

blemente aceptable, seguiría existiendo correlación entre el término de error y los regresores; en tal caso, se opta por el modelo de efectos fijos. Si, por el contrario, las estimaciones son significativamente iguales, se elige el modelo de efectos aleatorios. 
Cuadro 7. Resultados de la estimación con datos agrupados

(variable endógena: tasa de crecimiento del valor agregado censal bruto de la manufactura, $\left.y^{m}\right)$

\begin{tabular}{lccc}
\hline & Modelo 1 & Modelo 2 & Modelo 3 \\
\hline Constante & $3.552(0.000)$ & $1.715(0.018)$ & $1.718(0.018)$ \\
$\mathrm{y}^{\text {auto }}$ & $0.049(0.010)$ & $0.027(0.002)$ & $0.024(0.007)$ \\
$y_{E U}$ & & $0.293(0.039)$ & $0.281(0.048)$ \\
$y l_{\text {man }}$ & & $0.918(0.000)$ & $0.919(0.000)$ \\
$k^{\text {auto }}$ & 0.061 & & $0.006(0.254)$ \\
$R^{2}$ & 0.060 & 0.81 & 0.82 \\
$R^{2}$ ajustada & 0.78 & 0.78 \\
Estadístico $F$ & $6.789(0.010)$ & $151.45(0.000)$ & $114.27(0.000)$ \\
Prueba de datos & $0.782(0.685)$ & $1.42(0.158)$ & $1.58(0.101)$ \\
agrupados & & & \\
\hline
\end{tabular}

Nota: los valores entre paréntesis son la probabilidad del estadístico $t$. Son paneles balanceados con $n=15$, que corresponden al número de entidades federativas de México en las que se ubica la industria automotriz; $T=7$ años, que corresponden a la información censal para 1985, 1988, 1993, 1999, 2003, 2009 y 2013; 105 observaciones.

Fuente: Estimación realizada con R 2.15.3.

coeficiente de $k^{\text {auto }}$ se debe tomar con reserva, sobre todo, porque existe evidencia de que la inversión es un factor central en el crecimiento de la actividad económica. Al respecto, se ha sugerido que el factor determinante de la desaceleración en la tasa de expansión de la economía mexicana es el débil desempeño de la inversión fija bruta (Ros, 2008; Moreno-Brid y Ros, 2009). Incluso, se ha argumentado (Ros, 2013) que la inversión es central en el crecimiento económico de México.

\section{CONCLusiones}

Se identificaron algunas regularidades significativas, que se puntualizan a continuación:

a) El sector automotriz en México se ha concentrado en cuatro regiones principalmente, las que han respondido a una lógica económica diferenciada. En principio, la región Centro del país fue prioritaria para abastecer al mercado interno en el marco de una economía cerrada y altamente protegida. Posteriormente, el proceso de apertura económica - $\mathrm{y}$, de ma- 
nera específica, el inicio del TLCAN- propició el desplazamiento del sector hacia otras regiones, debido a la necesidad de abastecer a un creciente mercado externo y de responder a un nuevo modelo de características flexibles y mayores vínculos con el exterior.

b) La ubicación con respecto a la frontera norte se ha convertido en una ventaja muy importante por la cercanía con los mercados estadounidense y canadiense, de manera que las entidades federativas de esta franja fronteriza se convierten en destinos naturales para las nuevas inversiones automotrices. En estas entidades, a partir de finales de los setenta y principios de los ochenta, se empezaron a establecer importantes complejos automotrices conformados por ensambladoras y proveedoras de partes. Por ello, la región Norte se ha convertido en la más dinámica y competitiva del sector, llegando a conformar un importante conglomerado.

c) Con respecto a la región Centro-Norte, la presencia de armadoras como General Motors y Volkswagen, en Guanajuato, y General Motors, en San Luis Potosí, ha generado una importante dinámica local, con la que se ha incrementado sustancialmente la presencia de productoras de partes de primero, segundo y tercer niveles.

d) La región Occidente, conformada por los estados de Jalisco y Aguascalientes, aun sin crecimientos espectaculares de su industria automotriz, sí ha presentado una evolución constante y progresiva, sobre todo a partir del establecimiento de la planta de Honda en El Salto, Jalisco, y dos más de Nissan en Aguascalientes. A partir de ello se ha estimulado también el establecimiento de proveedores de partes de primer y segundo nivel.

e) Con relación a la dinámica de crecimiento a partir de las tasas de crecimiento del PIB real y la población ocupada en la manufactura y en el sector automotriz, se observa que éste es más dinámico. Sus tasas de crecimiento han sido superiores a las de la manufactura y muestra mayor sensibilidad a los impactos externos, tanto en los periodos de crisis como en los de recuperación. Además, se observa una correlación importante entre el crecimiento de la producción de ambos sectores y el del empleo, así como en la evolución de la producción de la manufactura y de la automotriz, lo que permitiría suponer que ésta incide en el crecimiento de aquélla. 
f) Se observó que la participación de la industria automotriz en la manufactura se ha incrementado de manera notable en los últimos treinta años: de 9.5\% del VACB total de la manufactura nacional, en 1980, a $14.4 \%$, en 2009. El sector automotriz de la región Centro es el que ha presentado un incremento más moderado en sus aportaciones a la manufactura, mientras que en las otras tres regiones han sido mucho más significativos.

g) Los resultados de la estimación, hecha a partir una analogía con la primera ley de Kaldor, revelan una correlación positiva entre el crecimiento de la producción de la industria automotriz $\left(y^{\text {auto }}\right)$ y el de la manufactura $\left(y^{m}\right)$, con lo que se puede plantear que la industria automotriz puede convertirse en un sector de impulso a la manufactura. Además, se reporta una correlación importante entre la economía mexicana, específicamente la manufactura, y la de Estados Unidos $\left(y_{E U}\right)$, sobre todo, por el peso que tiene la productividad $\left(y l_{\text {man }}\right)$.

Es importante destacar que aun cuando el coeficiente de la producción automotriz $\left(y^{\text {auto }}\right)$ es relativamente bajo (entre 0.024 y 0.049 ), el sentido económico del resultado nos proporciona argumentos para sostener que se está dando una relación positiva muy importante entre el crecimiento de la producción automotriz y el de la manufacturera, lo que implicaría un efecto de impulso. Quizá la magnitud del coeficiente se explique por la gran heterogeneidad en el crecimiento de las regiones, que, como se ha mencionado, se ha concentrado en la Norte y la Centro-Norte.

Finalmente, la industria automotriz ha representado para las entidades federativas que conforman las cuatro regiones analizadas la posibilidad de dinamizar su actividad económica. La evidencia muestra que la aportación de este sector a la manufactura, en términos del VACB y empleo, ha crecido de manera muy importante en los últimos años, lo que nos da elementos para suponer que la automotriz es una de las industrias prioritarias para el crecimiento de la manufactura y económico, en general, de las regiones donde se localiza.

\section{REFERENCIAS BIBLIOGRÁFICAS}

Álvarez, Lourdes (2010), "Industria automotriz en México y en Brasil: una comparación de resultados después de la crisis económica de 2008”, en Asociación Nacional de Facultades y Escuelas de Contaduría y Administración, Memoria xv Congreso Internacional de Contaduría, Administración e Informática, unAM, 
pp. 2-17. [en línea] Consultado el 23 se septiembre de 2014, en: http://congreso. investiga.fca.unam.mx/docs/xv/docs/174.pdf.

Álvarez, Lourdes, y Cuadros, Liliana (2012), "Las importaciones chinas y su impacto en el mercado de autopartes de repuesto mexicano", Problemas del Desarrollo, 43 (169), pp. 97-119.

Asociación Mexicana de la Industria Automotriz (2014), "Boletín de prensa. Diciembre 2013”. Consultado el 11 de marzo de 2015, en: http://www.amia.com.mx/ estadisticasvm.html.

Becerril, Dinorah (2013), "Industria automotriz, con 60 proveedores Tier 1", El Economista, 17 de mayo [en línea]. Consultado el 9 de mayo de 2013, en: http:// eleconomista.com.mx/estados/2013/05/07/industria-automotriz-60-proveedores-tier-1.

Camarena, Margarita (1981), La industria automotriz en México, México, UNAM.

Carbajal, Yolanda (2012), "El sector automotriz en el Estado de México. Condiciones y retos de la cadena productiva", Paradigma Económico, 4 (2), pp. 29-59.

(2013), "La competitividad de la industria automotriz en el Estado de México: condiciones y retos de la cadena automotriz-autopartes", tesis de Doctorado, Facultad de Economía, UNAM.

(2015), Evolución, condiciones actuales y retos del sector automotriz en México y en el Estado de México, Toluca, UAEM/ITiam.

Carbajal, Yolanda, y Jesús, Leobardo de (2013), "El sector automotriz en México, un análisis regional”, en Pablo Mejía Reyes (coord.), Fluctuaciones cíclicas y crecimiento económico en México, México, Plaza y Valdez/UAEM, pp. 311-343.

Carrillo, Jorge y Ramírez, Miguel Ángel (1997), "Reestructuración, eslabonamientos productivos y competencias laborales en la industria automotriz en México", ponencia en el xx Congreso Internacional de la Asociación de Estudios Latinoamericanos, del 17 al 19 de abril, Guadalajara, México.

Castillo, Ramón; Díaz, Alejandro, y Fragoso, Edna (2004), "Sincronización entre las economías de México y Estados Unidos: el caso del sector manufacturero", Comercio Exterior, 54 (7), pp. 620-627.

Chamarro, María del Pilar (2013), "Desarrollo regional e inversión extranjera directa en el sector automotriz. Desempeño 2000-2009”, tesis de Doctorado, Universidad Nacional de Educación a Distancia.

Chiquiar, Daniel, y Ramos-Francia, Manuel (2005), "Trade and Business-Cycle Synchronization: Evidence from Mexican and us Manufacturing Industries", The North American Journal of Economics and Finance, 16 (2), pp. 187-216.

Dombois, Rainer (1990), “Economía política y relaciones industriales en la industria au- 
tomotriz mexicana", en J. Carrillo (coord.), La nueva era de la industria automotriz en México, México, El Colegio de la Frontera Norte.

Dussel, Enrique (2003), "Ser maquila o no ser maquila, ¿es esa la pregunta?", Comercio Exterior, 53 (4), pp. 328-336.

(2012), "The Auto Parts-Automotive Chain in Mexico and China. Co-Operation Potential?", The China Quarterly, 209, pp. 82-110.

Fragoso, Edna (2003), "Apertura comercial y productividad en la industria manufacturera mexicana", Economía Mexicana, nueva época, 12 (1), pp. 5-38.

Galicia-Bretón, Fabiola, y Sánchez-Juárez, Issac Leobardo (2011), "La industria automotriz y el fomento a las cadenas productivas en Sonora: el caso de la Ford en Hermosillo", Economía, Sociedad y Territorio, 11 (35), pp. 161-195.

Garza, Gustavo (1992), Desconcentración, tecnología y localización industrial en México, México, DF, El Colegio de México.

Godínez, Juan Andrés (2007), "Brasil y México: especialización productiva diferenciada y dependencia estructural 'renovada' en un contexto económico globalizado", Análisis Económico, 22 (49), pp. 5-30.

González, María Luisa (2014), "Jatco inaugura nueva planta en Aguascalientes”, El Financiero, 10 de septiembre. Consultado el 10 de septiembre de 2014, en: http:// www.elfinanciero.com.mx/economia/jatco-inaugura-nueva-plante-enaguascalientes.html.

Granger, Clive (1969), "Investigating Causal Relations by Econometric Models and Cross-spectral Methods", Econometrica, 37 (3), pp. 424-438.

Hsiao, Cheng (2003), Analysis of Panel Data, 2a. ed., United Kingdom, Cambridge University Press.

Humphrey, John, y Memedovic, Olga (2003), "The Global Automotive Industry Value Chain: What Prospects for Upgrading by Developing Countries", unIDo Sectorial Studies Series Working Papers. [en línea] Consultado el 9 de mayo de 2013, en: http://papers.ssrn.com/sol3/papers.cfm?abstract_id=424560.

Ibarra, Carlos (2008), "La paradoja del crecimiento lento de México", Revista de la CEPAL (95), pp. 83-102.

INEGI (1980), Censos económicos, México, INEGI.

(1986), Censos económicos, México, INEGI.

(1989), Censos económicos, México, INEGI.

(1994), Censos económicos, México, INEGI.

(1999), Censos económicos, México, INEGI.

(2004), Censos económicos, México, INEGI.

(2009), Censos económicos, México, INEGI. 
(2013), La industria automotriz en México, 2013, Serie Estadísticas Sectoriales, México, INEGI.

(2014a), Producto interno bruto y ocupación y empleo, Cuentas Nacionales, México, INEGI.

(2014b), Censos Económicos, INEGI, México.

(2015), "Producto interno bruto del total de las industrias manufactureras y de la industria automotriz", en Cuentas Nacionales del Banco de Información Económica. Consultado el 2 de febrero de 2016, en: http://www.inegi.org.mx/ sistemas/bie/?idserPadre $=102000260010005000500200$.

Juárez, Huberto (2005), "La industria proveedora de autopartes”, en Huberto Juárez, Arturo Lara y Carmen Bueno (coords.), El auto global, desarrollo, cooperación y competencia en la industria del automóvil, México, CONACYT/Benemérita Universidad Autónoma de Puebla/UAM-X/Universidad Iberoamericana.

Kaldor, Nicholas (1966), "Causas del lento crecimiento del Reino Unido”, Investigación Económica, 0 (167), pp. 9-27.

(1970), "The Case for Regional Policies", Scottish Journal of Political Economy, (18), pp. 337-348.

Lara, Arturo; Trujano, Gerardo, y García, Alejandro (2005), "Producción modular y coordinación en el sector de autopartes en México. El caso de la red de plantas de Lear Corporation", Región y Sociedad, 17 (32), pp. 33-71.

Lechuga, Jesús, y Varela, Mauricio (2001), "Empleo manufacturero en México, 19901998”, Análisis Económico, 16 (33), pp. 215-234.

Maldonado, Serafín (1995), "La rama automovilística y los corredores industriales en el noroeste de México”, Comercio Exterior, 45 (6), pp. 487-497.

Mejía, Pablo, y Campos-Chávez, Jeanett (2009), “Are the Mexican States and the United States Business Cycles Synchronized? Evidence from the Manufacturing Production", Economía Mexicana, nueva época, 20 (1), pp. 79-112.

Moreno, Álvaro Martín (2008), "Las leyes del desarrollo económico endógeno de Kaldor: el caso colombiano", Revista de Economía Institucional, 10 (18), pp. 129-147.

Moreno-Brid, Juan Carlos (1996), “México's Auto Industry after NAFTA: A Successful Experience in Restructuring?", working paper 232, The Helen Kellogg Institute International Studies, University of Notre Dame.

Moreno-Brid, Juan Carlos; Santamaría, Jesús, y Rivas, Juan Carlos (2006), "Manufactura y TLCAN: un camino de luces y sombras", Economía UNAM, 3 (8), pp. 95-114. Moreno-Brid, Juan Carlos, y Ros, Jaime (2009), Development and Growth in the Mexi- 
can Economy. A Historical Perspective, United States of America, Oxford University Press.

Ortega, Eduardo (2015), "Inaugura Peña Nieto ampliación de la carretera León-Lagos de Moreno", El Financiero, 28 de abril. Consultado el 28 de abril de 2015, en: http://www.elfinanciero.com.mx/bajio/inaugura-pena-nieto-ampliacion-de-lacarretera-leon-lagos-de-moreno.html.

Rendón-Rojas, Liliana, y Mejía, Pablo (2015), "Producción manufacturera en dos regiones mexiquenses: evaluación de las leyes de Kaldor", Economía, Sociedad y Territorio, 15 (48), pp. 425-454.

Reyes, Marlen Rocío; Rendón-Rojas, Liliana, y Mejía, Pablo (2016), “HHay evidencia de ciclo político-económico en el empleo sectorial de México, 1998-2013?”, Revista de Contaduría y Administración, próxima publicación. [en línea] Consultado el 4 de abril de 2016, en: http://www.cya.unam.mx/index.php/cya/article/ view/967.

Ros, Jaime (2008), "La desaceleración del crecimiento económico en México desde 1982", El Trimestre Económico, 75 (299), pp. 537-560.

(2013), Algunas tesis equivocadas sobre el estancamiento económico de México, México, El Colegio de México.

s.a. (2016), "Construirán un nuevo parque industrial destinado al procesamiento de plásticos en Aguascalientes", El Occidental, 24 de octubre. Consultado el 24 de octubre de 2016, en: http://www.oem.com.mx/eloccidental/notas/n3868899.htm.

Sánchez, Issac Leobardo (2012), "Ralentización del crecimiento y manufacturas en México", Nóesis, 21 (41), pp. 137-170.

Sánchez, Issac Leobardo, y Campos, Edgar (2010), "Industria manufacturera y crecimiento económico en la frontera norte de México", Región y Sociedad, 22 (49), pp. $45-89$.

Secretaría de Desarrollo Económico (2016), "Parques industriales", en Secretaría de Desarrollo Económico, Gobierno del Estado de Aguascalientes. Consultado el 24 de octubre de 2016, en: http://www.parquesindustrialesags.org/parques-industriales/.

Secretaría de Economía (2012), Programa estratégico de la industria automotriz 20122020. Subsecretaría de Industria y Comercio. [pdf] Consultado el 5 de febrero de 2016, en: http://www.economia.gob.mx/files/comunidad_negocios/industria_comercio/peia_ok.pdf .

(2016), "Estadística oficial de los flujos de IED hacia México", en Competitividad y Normatividad / Inversión Extranjera Directa de la Secretaría de Economía. Consultado el 10 de octubre de 2016, en: http://www.gob.mx/se/acciones-yprogramas/competitividad-y-normatividad-inversion-extranjera-directa. 
Sturgeon, Timothy; Memedovic, Olga; Biesebroeck, Johannes, y Gereffi, Gary (2009), "Globalisation of the Automotive Industry: Main Features and Trends", International Journal Technological Learning, Innovation and Development, 2 (1/2), pp. 7-24.

Sturgeon, Timothy, y Florida, Richard (2000), Globalization and Jobs in the Automotive Industry. [pdf] Cambridge, Industrial Performance Center/Massachusetts Institute of Technology. Consultado el 2 de febrero de 2016, en: https://ipc.mit.edu/ sites/default/files/documents/00-012.pdf.

Thirlwall, Anthony (2003), La naturaleza del crecimiento económico: un marco alternativo para comprender el desempeño de las naciones, México, Fondo de Cultura Económica.

Unger, Kurt (2003), Los clusters industriales en México: especializaciones regionales y la política industrial. Santiago de Chile, CEPAL.

(2004), "La industria automotriz en el Estado de México: una perspectiva de clusters regionales", en P. Mejía Reyes (coord.). La economía del Estado de México: hacia una agenda de investigación, Zinacantepec, El Colegio Mexiquense.

(2010), Globalización y clusters regionales en México: un enfoque evolutivo, México, Fondo de Cultura Económica.

Unger, Kurt, y Chico, Roberto (2004), "La industria automotriz en tres regiones de México. Un análisis de clusters", El Trimestre Económico, 71 (284), pp. 909-941.

Vicencio, Arturo (2007), "La industria automotriz en México, Antecedentes, situación actual y perspectivas", Contaduría y Administración, 0 (221), pp. 211-248.

Vieyra, Antonio (1999), El sector automotriz en el proceso de industrialización en México: aspectos histórico-económicos de su conformación territorial, México, UNAM.

(2000), "Reconversión industrial, gran empresa y efectos territoriales: El caso del sector automotriz en México”, EURE, 26 (77), pp. 25-47.

Villarreal, Diana Rebeca, y Villegas, Marcela (2005), Cambios en la localización de la industria automotriz en México 1994-2004, México, Universidad Autónoma Metropolitana. 